\title{
Stable Radical-Anions Derived from Glyoxal Bis(phenylhydrazones)*
}

\author{
Alexander J. Fatiadi \\ Institute for Materials Research, National Bureau of Standards, Washington, D.C. 20234 \\ (May 10, 1971)

\begin{abstract}
A series of resonance-stabilized, hydrazyl radical-anions has been observed for the first time; they were prepared by an electron-transfer reaction involving treatment of glyoxal bis(phenylhydrazones) in methyl sulfoxide with a base and a trace of oxygen. The stability of these radical-anions appears to be dependent on the nature of the para substituents on the phenylhydrazine moiety.
\end{abstract} \\ Key words: Bis(phenylhydrazone); e.s.r.; glyoxal; methyl sulfoxide; oxygen; radical-anion.
}

\section{Introduction}

In the series of stable hydrazyl radicals, a neutral radical, namely, 1,1-diphenyl-2-picrylhydrazyl (DPPH), and its analogs are the best known and the most thoroughly studied $[1,2] ;{ }^{1}$ recently, e.s.r. studies established the existence of stable, hydrazinium radical-cations in colored solutions of tetraphenylhydrazine dissolved in strong acids [3]. The present report describes the preparation and some of the properties of some new, stable, hydrazyl radicalanions.

\section{Experimental Procedure}

\subsection{Apparatus}

Ultraviolet and visible spectra were recorded with a Beckman DK-2 or Cary 14 spectrophotometer." Electron-spin resonance spectra were recorded with a Varian Model 4500 EPR spectrometer with 100$\mathrm{kHz}$ field-modulation and detection. The klystron frequency was measured with a transfer oscillator and a frequency counter. The magnetic field was measured by a proton gaussmeter monitored by the same frequency counter.

The solutions were examined in a Varian Model V-4548 aqueous-solution sample-cell. All experiments in solution required a trace of oxygen; freshly prepared solutions of bis(phenylhydrazones) in methyl sulfoxide (2.5 to $5.0 \mathrm{~m} M$ ) were mixed with base $(5 \%$ aqueous potassium hydroxide or $5 \%$ potassium tert-butoxide in methyl sulfoxide) and exposed to air for about $30 \mathrm{~s}$. Initial e.s.r. spectra were recorded about $1 \mathrm{~min}$ after mixing.

\footnotetext{
* Part II. Stable Free Radicals. For part I, see Chem. Commun. 456 (1968).

${ }^{1}$ Figures in brackets indicate the literature references at the end of this paper.

${ }^{2}$ Certain commercial instruments or chemicals are mentioned in this paper; this does not imply recommendation or endorsement by the National Bureau of Standards.
}

\subsection{Materials}

Methyl sulfoxide (Matheson spectrograde) and a reagent-grade potassium tert-butoxide (Mine Safety Appliances Research Corp.) were used directly.

Glyoxal bis(phenylhydrazones) were prepared by condensation of 40 percent aqueous glyoxal (Union Carbide Chemicals) with phenylhydrazine or with $p$-bromo-, $p$-chloro-, 2,5-dichloro, $p$-nitro- or $m$-nitrophenylhydrazine in the presence of a catalytic amount of acetic acid; the crude bis(phenylhydrazones) were purified by repeated recrystallization from ethanol or ethanol-acetic acid.

The $\mathrm{C}_{6} \mathrm{D}_{5} \mathrm{NHNH}_{2}$ was prepared according to the following scheme:

$$
\begin{aligned}
\mathrm{C}_{6} \mathrm{D}_{5} \mathrm{NO}_{2} \frac{\mathrm{Sn}}{\mathrm{HCl}} \mathrm{C}_{6} \mathrm{D}_{5} \mathrm{NH}_{2} \cdot \mathrm{HCl} \stackrel{\begin{array}{l}
\text { (1) } \mathrm{NaOH} \\
\text { (2) steam distillation }
\end{array}}{\text { (3) ether extraction }} \\
\mathrm{C}_{6} \mathrm{D}_{5} \mathrm{NH}_{2} \frac{\mathrm{NaNO}_{2}, \mathrm{HCl}^{\circ}}{0^{\circ}} \mathrm{C}_{6} \mathrm{D}_{5} \stackrel{+}{\mathrm{N}} \equiv \mathrm{NCl}^{-} \\
\stackrel{\mathrm{Na}_{2} \mathrm{SO}_{3}}{\longrightarrow} \mathrm{C}_{6} \mathrm{D}_{5} \mathrm{NHNH}_{2} \cdot \mathrm{HCl}(45 \% \text { overall yield). }
\end{aligned}
$$

\section{Results and Discussion}

Treatment of a solution of glyoxal bis(phenylhydrazone) 1 a in methyl sulfoxide $\left(\mathrm{Me}_{2} \mathrm{SO}\right)\left(10^{-2}\right.$ to $\left.10^{-3} M, \lambda \underset{\max }{\mathrm{Me}_{2} \mathrm{SO}} 382 \mathrm{~nm}, \epsilon_{\mathrm{m} M} \sim 49\right)$ with a strong base $(5 \%$ aqueous potassium hydroxide or potassium tert-butoxide in $\mathrm{Me}_{2} \mathrm{SO}$ ) and a trace of oxygen produced a deep violet-purple solution exhibiting bands at $\lambda_{\max } 455$ and $562 \mathrm{~nm}$ with rapidly changing intensity. E.s.r. examination of the solution revealed that the deep-purple color, and consequently a batho- 


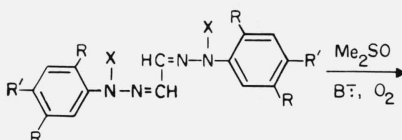

(1)
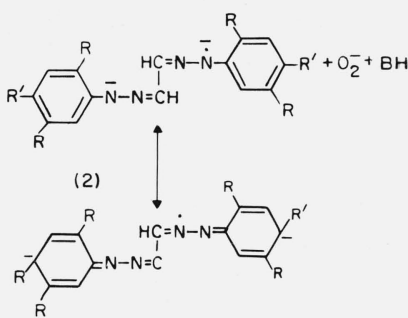

(2)

(2a) $R=R^{\prime}=H$

(2b) $\mathrm{R}=\mathrm{Cl}, \mathrm{R}^{\prime}=\mathrm{H}$

(2c) $R=H, R^{\prime}=B r$

(2d) $R=R^{\prime}=\mathrm{H}, \mathrm{R}=\mathrm{m}-\mathrm{NO}_{2}$

(Id) $R=X=H, R^{\prime}=C l, B r$

(le ) $R=X=H, R^{\prime}=\mathrm{NO}_{2}$

(If) $R=R^{\prime}=H, R=m-N_{2}$

$\begin{aligned} \mathrm{HC}=\mathrm{N}-\dot{\bar{N}}-\longrightarrow & -\mathrm{N}-\mathrm{C}=\mathrm{CH}\end{aligned}$

A

$\stackrel{\mathrm{H}}{\longrightarrow}$

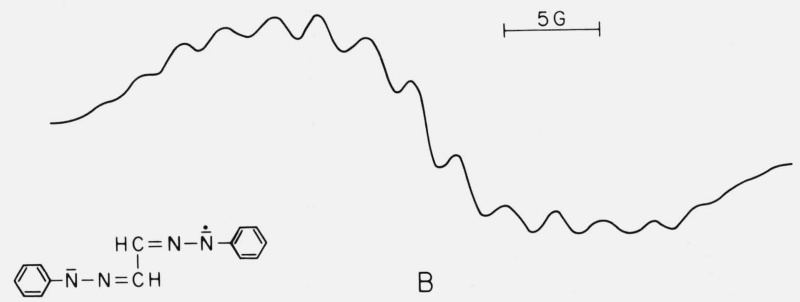

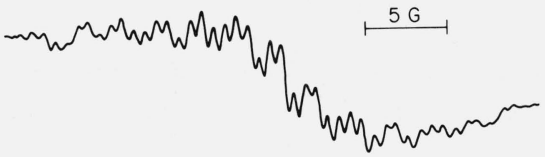

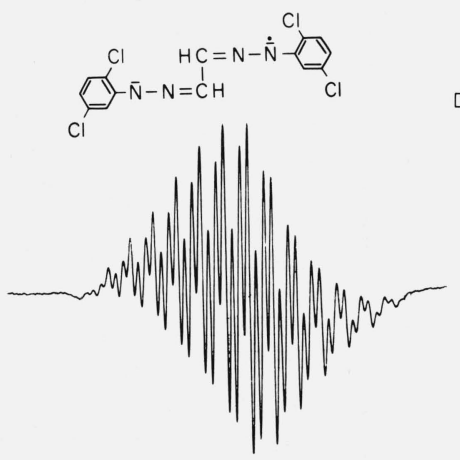

C

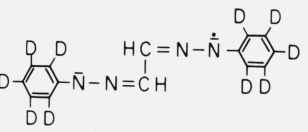

$\underset{-C=N-\bar{N}-N=C H}{-N}$

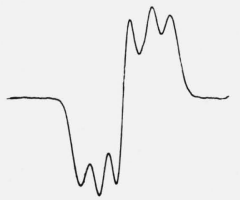

D $\quad 10 G$

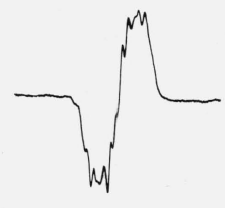

E $\stackrel{15 G}{\square}$

FIGURE 1. Radical-anions from glyoxal bis(phenylhydrazones); A, from 1 a $(3.2 \mathrm{mM}$, in $\mathrm{Me}_{2} \mathrm{SO}-5$ percent aqueous $\left.\mathrm{KOH}\right) ; B$, from 1 a $\left(2.8 \mathrm{mM}\right.$, in $\left.\mathrm{Me}_{2} \mathrm{SO}-\mathrm{KOBu}^{\mathrm{t}}\right)$; $C$, from 2,5-dichloro derivative of $\mathbf{1 a}\left(3 \mathrm{mM}\right.$, in $\left.\mathrm{Me}_{2} \mathrm{SO}-\mathrm{KOBu}^{t}\right) ; D$, from $\mathbf{1 a}$, completely substituted with deuterium on the benzene ring ( $5 \mathrm{mM}$, in $\left.\mathrm{Me}_{2} \mathrm{SO}-\mathrm{KOBu}^{\mathrm{t}}\right)$; E, from phenylglyoxal bis(phenylhydrazone). 
chromic shift in the visible spectrum, is partly associated with the presence of a paramagnetic species having the hyperfine structure shown in figures 1A and $1 \mathrm{~B}$.

Cooling and rapid filtration of the concentrated, alkaline solution from $\mathbf{I A}$ yielded a somewhat airsensitive, purple-violet, paramagnetic dipotassium salt $(\mathbf{2} \leftrightarrow \mathbf{2 a})$. From the fact that neither the $N$ methyl nor the $N$-benzoyl derivative of glyoxal bis(phenylhydrazone) (1) and lc, respectively) showed either a color change or the presence of paramagnetic species following treatment with base, it was concluded that the purple radical-anion from la must arise following the abstraction of acidic imino protons ( $\mathrm{X}$ in $\mathbf{l} \mathbf{a}$ ) by base. The dianion character of the radical anion $(\mathbf{2} \leftrightarrow \mathbf{2} \mathbf{a})$ was deduced from the fact that methylation or benzoylation of the latter gave the di- $N$-methyl $(\mathbf{l b})\left(\mathrm{mp} .224{ }^{\circ} \mathrm{C}\right)$ or $\mathrm{di}-N$ benzoyl (1c) (mp. $312{ }^{\circ} \mathrm{C}$. derivative of glyoxal bis(phenylhydrazone) in 45 and 60 percent yield, respectively.

The contribution of the resonance form $(\mathbf{2} \leftrightarrow \mathbf{2} \mathbf{a})$ to the stability of the radical anion from la was deduced from a study of radical anions derived from the substituted bis(phenylhydrazones). The most stable radicalanions were obtained from (a) the unsubstituted glyoxal bis(phenylhydrazone) la, (b) those having the paraposition in the benzene ring unsubstituted (for example, the 2,5-dichloro derivative, $\mathbf{2} \mathbf{b}$ ), or (c) those in which the para-position was substituted with an electronwithdrawing group, for example, the $p$-nitro derivative le. Derivatives having electron-donating groups on the phenylhydrazino group (for example, the $p$-chloro or $p$-bromo derivatives ld) produced, on treatment with base, little or no bathochromic shift and gave little or no e.s.r. signal. These observations are in agreement with the substituent effect proposed by Walter [4], in which it was considered that electron-withdrawing groups (e.g., $p$ - $\mathrm{NO}_{2}$ ) enhance the stability of the hydrazyl radical by delocalization of an unpaired electron. It may be mentioned, however, that in contrast to neutral and cationic hydrazyl radicals having $p$ - $\mathrm{Cl}$ or $p$ - $\mathrm{Br}$ substituents, the corresponding anion-radical of type 2c was not observed following treatment of the glyoxal $p$-Cl- or $p$-Br-substituted bis(phenylhydrazones) Id with base. ${ }^{3}$ Formation of a radical anion $(\mathbf{2} \leftrightarrow \mathbf{2 a})$ from the bis(phenylhydrazone) la in the presence of oxygen and base appears to be a straightforward example of electron transfer; similar electron transfer occurs in the formation of radical anions from formazans [5]. The contribution of the resonance form $(\mathbf{2} \leftrightarrow \mathbf{2} \mathbf{a})$ to the stability of the radical anion from la was also supported by the fact that examination of the residue obtained after acidification with dilute hydrochloric acid of the alkaline paramagnetic solution from la revealed the presence of a trace of the oxidation product 1,2-bis(phenylazo)ethylene 5. This indicates that only a negligible proportion of a tautomer anion (as shown) is involved in the resonance form.

${ }^{3} \mathrm{~A}$ very weak, one-line e.s.r. spectrum $\left[\Delta H(\right.$ width $\left.)=21.6 \mathrm{G}, g_{m}=2.007\right]$ was observed for the radical anion from the bis(p-chloro- $o$-methoxyphenylhydrazone) of glyoxal.
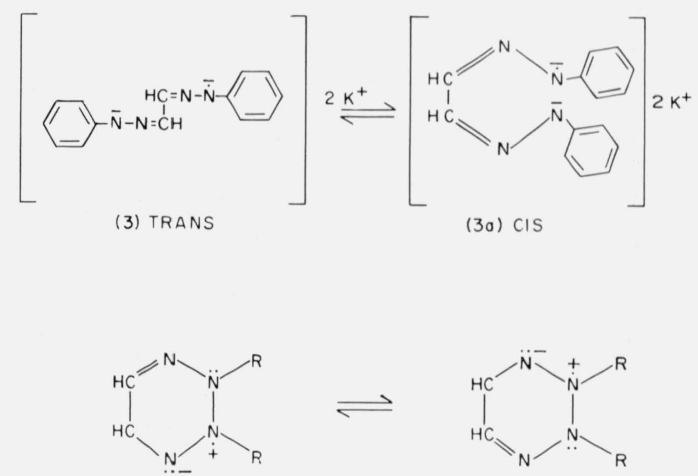

(4)

(4a)

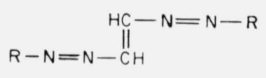

$\mathrm{R}=\mathrm{C}_{6} \mathrm{H}_{5}$

(5)

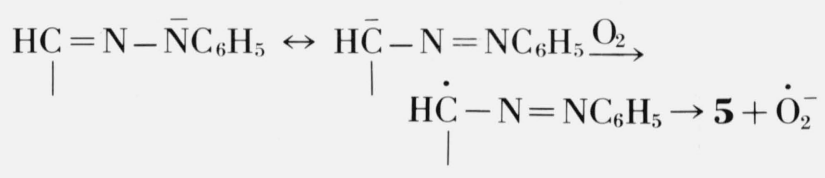

or the resonance form

$\underset{\mathrm{H}}{\mathrm{C}}-\mathrm{N}=\mathrm{NC}_{6} \mathrm{H}_{5} \leftrightarrow \mathrm{HC}=\mathrm{N}-\dot{\mathrm{NC}}_{6} \mathrm{H}_{5}$

(only half of la is depicted).

The radical anion from la (or its analogs $\mathbf{2 b}$ or $\mathbf{2 d}$ ) is stable in air for over an hour (dilute solution in $\mathrm{Me}_{2} \mathrm{SO}$ ); in concentrated solution, especially with limited access of air, the e.s.r. signals persist for at least $24 \mathrm{~h}$; signals were not observed in methanol, $p$-dioxane, or their aqueous mixtures as solvent.

Bis(phenylhydrazone) la gave the e.s.r. spectra shown in figures 1 and 2 . The 15-line spectra $\mathrm{A}$ and $\mathrm{A}-1$ (aqueous potassium hydroxide) with intensities of $\sim 1: 2: 6: 10$ : $14: 18: 22: 24: 22: 18: 14: 10: 6: 2: 1$ were observed. Structure A represents a centrosymmetric, resonancestabilized, radical anion having two different pairs of nitrogen atoms $(\mathrm{N}=\mathrm{CH}$ and $\mathrm{N}-\mathrm{Ph})$; the e.s.r. spectrum (A and A-l, figs. 1 and 2) can be explained by assuming interaction of the unpaired electron with two pairs of equivalent nitrogen atoms; this spectrum is consistent with $a^{\mathrm{N}}=4.95$ and $4.95 \mathrm{G}, a^{\mathrm{H}}=4.95,4.95$, 2.35 , and 2.35 G. Spectrum B (fig. 1) (prepared with anhydrous potassium tert-butoxide in methyl sulfoxide) is consistent with $a^{\mathrm{N}}=5.70$ and $5.70 \mathrm{G} ; a^{\mathrm{H}}=5.70,5.70$, $1.41,1.41,0.70$, and $0.70 \mathrm{G}^{4}{ }^{4}$ The radical intermediate may be represented as a resonance-stabilized, acyclic

\footnotetext{
${ }^{4}$ The 15-line spectra $\mathrm{A}$ and $\mathrm{A}-\mathrm{l}$ (figs. 1 and 2) are indicative of the unpaired electron interacting with two pairs of equivalent nitrogen atoms and two equivalent hydrogen atoms (or their equivalent pairs) or $\left(\mathrm{N}-\mathrm{N}_{2} \mathrm{H}_{3}\right.$

The observed 40-line spectra for $\mathrm{B}$ and $\mathrm{C}$ (fig. 1, which could have some overlap) fits $(\mathrm{N}-\mathrm{N})_{2} \mathrm{H}_{7}$, whereas $(\mathrm{N}-\mathrm{N})_{2} \mathrm{H}_{6}$ should give a 35 -line pattern.
} 


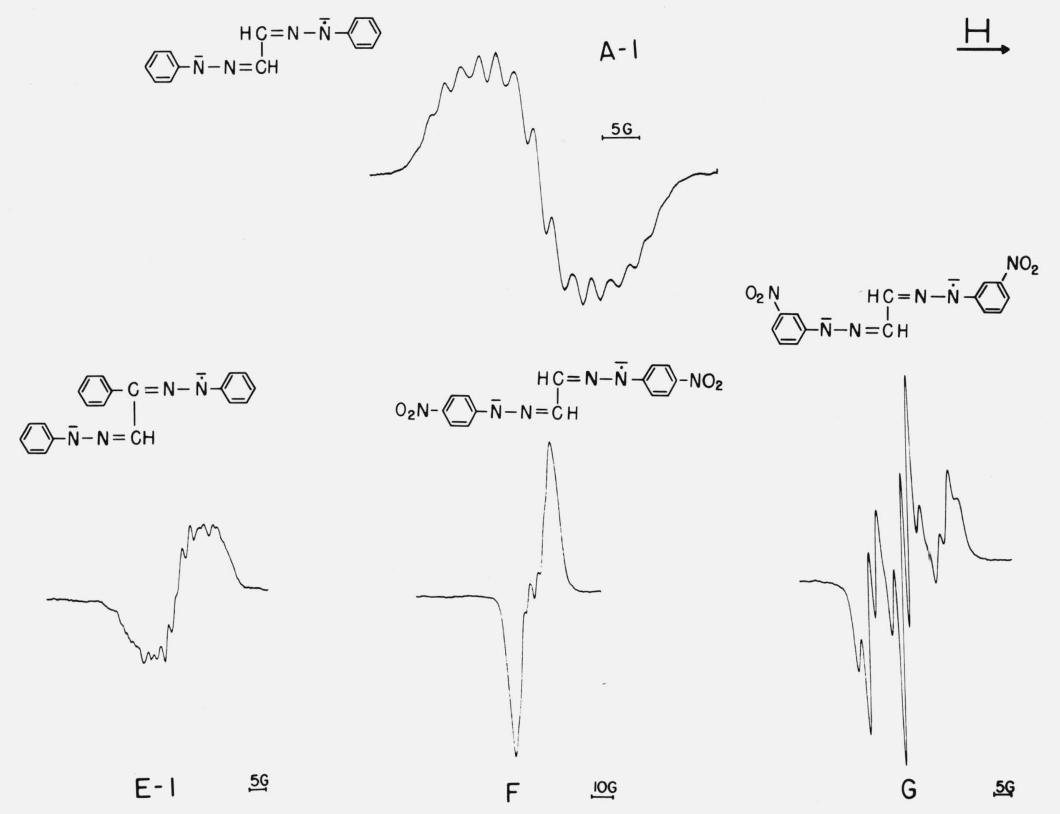

Figure 2. Radical-anions from glyoxal bis(phenylhydrazones): A-1, from 1 a (3.8 $m M$, in $\mathrm{Me}_{2} \mathrm{SO}-5$ percent aqueous $\left.\mathrm{KOH}\right) ; E-1$, from phenylglyoxal bis(phenylhydrazone) (3.3 mM, in $\left.\mathrm{Me}_{2} \mathrm{SO}-\mathrm{KOBu}^{\mathrm{t}}\right) ; \mathrm{F}$, from $\mathrm{p}-\mathrm{NO}_{2}$ phenylglyoxal bis(phenylhydrazone 1e, $2.75 \mathrm{mM}$, in $\left.\mathrm{Me}_{2} \mathrm{SO}-\mathrm{KOBu}^{t}\right) ; G$, $\mathrm{m}^{-\mathrm{NO}_{2}}$ derivative $2 d(3.5 \mathrm{mM}$, in $\mathrm{Me}_{2} \mathrm{SO}-\mathrm{KOBu}^{\mathrm{t}}$.

structure (trans-cis structures $\mathbf{3} \leftrightarrow \mathbf{3 a}$ ), mainly sterically favored anti-anti form 3 [6]; three geometrical isomers of the glyoxal bis(phenylhydrazones) are possible: anti, syn, and amphi, (see reference $[6,10 \mathrm{c}]$ for the discussion). However, some cyclic 1, 2, 3, 4-tetrazine structure $(\mathbf{4} \leftrightarrow \mathbf{4 a})$ cannot be excluded completely. Further examination of the residue obtained after neutralization of the original purple solution from 1 a with aqueous hydrochloric acid, showed, in addition to the starting material, only a trace of the azo derivative 5; the mixture contained [by preparative t.l.c. on Silica Gel G with 1:4 (v/v) ethanol-benzene] a small proportion of an orange component ${ }^{5}$ believed to be a derivative of the cyclic 1,2,3,4-tetrazine [8-10]. The cyclic structures of the radical intermediates from formazans and tetrazolium salts involving 4-nitrogen nuclei were proposed by Maender and Russell [4a]; the stable radical derived from the cyclic 1,2,4,5-tetrazines (also comprising 4 nitrogen-nuclei) were recently reported [11]; the radical anion derived, for example, from 2,5-dialkyl-substituted 1,2,4,5-tetrazine showed an e.s.r. feature consisting of 63 lines [12].

N.M.R. studies of the bis(phenylhydrazones) of glyoxal (1a) in methyl sulfoxide gave evidence for the existence of a chelated and a nonchelated $\mathrm{N}-\mathrm{H}$ group, prototype structures $3 \leftrightarrow \mathbf{3 a}$ [6] [7]; addition of a strong base, however, produced a paramagnetic solution, and caused disappearance of the $\mathrm{N}-\mathrm{H}$ chelated bond. For example, an N.M.R. signal due to a chelated $\mathrm{N}-\mathrm{H}$ in

\footnotetext{
${ }^{5}$ Irradiation $(366 \mathrm{~nm})$ of a 1 percent solution of $1 \mathbf{a}$ in benzene, gave a blue fluorescent com-
ponent, in addition to a starting material and 5 [t.1.c. $3: 1(\mathrm{v} / \mathrm{v})$ benzene-methyl alcohol]; the ponent, in addition to a starting material and $\mathbf{5}$ [t.l.c. $3: 1(\mathrm{v} / \mathrm{v})$ benzene-methyl alcohol]; the
mixture also contained a brown-orange component (by preparative t.l.c.) that on treatment with $\mathrm{KOBu}^{1}-\mathrm{Me}_{2} \mathrm{SO}$ produced an e.s.r. spectrum similar to A (fig. 1). The compound may with $\mathrm{KOBu}^{\mathrm{i}}-\mathrm{Me}_{2} \mathrm{SO}$ produce
have a structure $(\mathbf{4} \leftrightarrow \mathbf{4 a})$.
}

$\mathbf{l a}$ at $12.55 \mathrm{ppm}$ (in methyl sulfoxide, after equilibration) [7], disappears on addition of $0.1 \mathrm{ml}$ of 5 percent solution of potassium tert-butoxide (in $\mathrm{Me}_{2} \mathrm{SO}$ ) to the probe; the same happens to a signal at $12.25 \mathrm{ppm}$ (chelated $\mathrm{H}-\mathrm{H}$ ) in $p$ - $\mathrm{NO}_{2}$ derivative le.

The oxidative radical dimerization and coupling in the phenylhydrazine series is well known [13-17].

A symmetrical radical-anion $\mathbf{2 b}$ derived from glyoxal bis[(2,5-dichlorophenyl)hydrazone] gave the e.s.r. features shown in figure $1 \mathrm{C}$; this is also explained by assuming interaction of the unpaired electron with two pairs of equivalent nitrogen atoms $a^{\mathrm{N}}=6.35$ and $6.35 \mathrm{G}$; $a^{\mathrm{H}}=6.35,6.35,1.65,1.65,0.82$, and $0.82 \mathrm{G}$.

The hyperfine splitting constant (h.f.s.c.), which is a function of the spin densities, is somewhat larger for the radical $2 \mathbf{b}\left(a^{N}=6.35 \mathrm{G}\right)$ than for the radical derived from the unsubstituted bis(phenylhydrazone) of glyoxal $\mathbf{l a}\left(a^{N}=4.95 \mathrm{G}\right.$ or $5.70 \mathrm{G}$, see table 1$)$. This can be explained by the electron-donating character of the 2,5-dichloro substituents, which results in an increase in the spin density on the 4 nitrogen nuclei of the molecule (the para-position in the benzene ring of $\mathbf{2} \mathbf{b}$ is free to participate in the resonance).

In an attempt to find an unequivocal proof for the magnetic equivalence of four nitrogen atoms or their pairs in radical-anions $2 \mathbf{a}$ and $\mathbf{2 b}$ (fig. $1 \mathrm{~A}, 1 \mathrm{~B}$, and $1 \mathrm{C}$ ), the e.s.r. spectrum of glyoxal bis(phenylhydrazone) completely substituted with deuterium on the benzene ring was measured; this gave an incomplete pattern (fig. 1D); the spectrum did not show 4 nitrogen nuclei, and the quintet observed having h.f.s.c. $a^{\mathrm{N}}=5.45 \mathrm{G}$ is evidently a portion derived from two magnetically equivalent nitrogen atoms.

The radical anion derived from phenylglyoxal bis- 
TABLE 1. Hyperfine splitting constants and $\mathrm{g}_{\mathrm{m}}$ values $^{\mathrm{a}}$ of radical anions of substituted bis(phenylhydrazones) of glyoxal at $25 \pm 3^{\circ}$

\begin{tabular}{|c|c|c|c|c|c|}
\hline Compound No. & Spectrum & Solvent & $\mathrm{g}_{m}$ value $^{\mathrm{b}}$ & $\begin{array}{c}\text { Hyperfine structure } \\
a^{N}(\mathrm{G})\end{array}$ & $\begin{array}{l}\text { No. of equivalent } \\
\text { nitrogen atoms }\end{array}$ \\
\hline $\begin{array}{l}2 \mathbf{a} \\
2 \mathbf{b} \\
2 \mathbf{d}\end{array}$ & $\begin{array}{l}A-l^{d} \\
B^{e} \\
C \\
D \\
\text { E } \\
\text { E-1 } \\
G \\
F\end{array}$ & $\begin{array}{r}{ }^{\mathrm{c}} 1 \\
2 \\
2 \\
2 \\
2 \\
2 \\
2 \\
2 \\
2\end{array}$ & $\begin{array}{l}2.0035 \pm 0.0001 \\
2.0041 \pm 0.0001 \\
2.0044 \pm 0.0002 \\
2.0042 \pm 0.0003 \\
2.0043 \pm 0.0001 \\
2.0044 \pm 0.0001 \\
2.0053 \pm 0.0002 \\
2.0059 \pm 0.0003\end{array}$ & $\begin{array}{l}4.95,4.95 \\
5.70,5.70 \\
6.35,6.35 \\
5.45 \\
4.40,4.40 \\
7.05 \quad\end{array}$ & $\begin{array}{l}\text { Two pairs. } \\
\text { Two pairs. } \\
\text { Two pairs. } \\
\text { Two. } \\
\text { Two pairs. } \\
\text { Four. }\end{array}$ \\
\hline
\end{tabular}

\footnotetext{
a Indicated errors of all values in this table are standard deviations of the average for three determinations; for example, for the $a^{\mathrm{N}}$ values the average deviation is \pm 0.15 $\mathrm{g}_{m}$ is defined as the middle point of the hyperfine lines of the spectrum.

1, $\mathrm{Me}_{2} \mathrm{SO}$-aqueous $\mathrm{KOH} ; 2$, $\mathrm{Me}_{2} \mathrm{SO}-\mathrm{KOBu}^{t}$

${ }^{a}$ Radical concentration (range from 12 to $38 \%$ ), based on starting bis(phenylhydrazones), was determined by comparison with a diphenylpicrylhydrazyl standard solution. E.s.r. spectrum of $2 \mathbf{a}$ measured at $77 \mathrm{~K}$ gave one line $\left(g_{\perp}=1.99, \Delta H=19.3 \mathrm{G}\right)$.

'Poorly resolved splitting.

Distribution of Intensity.
}

(1) For Equivalent Nitrogens

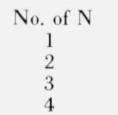

No. Lines
3
5
7
9

\section{Pattern}

$1: 2: 3: 2: 1$

$1: 3: 6: 7: 6: 3: 1$

$1: 4: 10: 16: 19: 16: 10: 4: 1$

(phenylhydrazone) (fig. 1E) did not show a well-resolved e.s.r. spectrum, a e.s.r. spectrum of the same radicalanion that is somewhat better resolved is shown in (fig. $2 \mathrm{E}-1)$. The 15-line pattern can be explained by assuming interaction of the unpaired electron with two pairs of equivalent nitrogen atoms, the spectrum $(E-1)$ is consistent with $a^{\mathrm{N}} \sim 4.40$ and $4.40 \mathrm{G} . a^{\mathrm{H}} \sim 4.40,4.40$, 2.60 , and $2.60 .^{6}$

The radical anions derived from glyoxal bis[( $p$ nitrophenyl)hydrazone]le (spectrum F, fig. 2) showed a poorly resolved e.s.r. spectrum (apparently a portion of a 9-line pattern) a split (in the middle of a strong line) into three weak lines having a separation $a^{\mathrm{N}} \sim 4.25$ $\mathrm{G}, g_{m}=2.006$. On the other hand, the radical anion derived from the $m$-nitro derivative $\mathbf{I f}$ (spectrum $\mathrm{G}$ fig. 2 ) showed a well-resolved, 9-line pattern indicative of interaction of the unpaired electron with four magnetically equivalent nitrogen atoms, with the hyperfine splitting constant $a^{\mathrm{N}}=7.05 \mathrm{G}$.

The author thanks N. Adams (NBS) for the e.s.r. measurements, and R. Schaffer for his interest in this work.

${ }^{6}$ The average deviations: $a^{\vee} 4.40 \pm 0.25, a^{H} 2.60 \pm 0.22$.
(2) For Equivalent Hydrogen

$\begin{array}{ccl}\text { No. of } \mathrm{H} & \text { No. Lines } & \text { Pattern } \\ 1 & 2 & 1: 1 \\ 2 & 3 & 1: 2: 1 \\ 3 & 4 & 1: 3: 3: 1 \\ 4 & 5 & 1: 4: 6: 4: 1\end{array}$

\section{References}

[1] Buchachenko, A. L., Stable Radicals, pp. 100-144 (consultants Bureau, New York, 1965)

[2] Forrester, A. R., Hay, J. M., and Thomson, R. H., Organic Chemistry of Stable Free Radicals, pp. 137-179 (Academic Press, New York, 1968).

[3] (a) Razuvaez, G. A., Abakumov, G. A., and Pestunovich, V. A., J. Struct. Chem. 5, 278 (1964); (b) Ref. [2], pp. 122-125.

[4] Walter, R. J., J. Amer. Chem. Soc. 88, 1923 (1966); Ref. [2], pp. $5,115-116$.

[5] (a) Maender, O. W. and Russell, G. A., J. Org. Chem. 31, 442 (1966); (b) Russell, G. A., Radical Ions, Kaiser, E. T. and Kevan, L. Ed., p. 87 ff (Interscience, New York, 1968).

[6] Chapman, O. L., King, R. W., Welstead, W. J., Jun., and Murphy, T. J., J. Amer. Chem. Soc. 84, 4968 (1964).

[7] Fatiadi, A. J. and Isbell, H. S., Carbohyd. Res. 5, 302 (1967).

[8] Katritzky, A. R. and Lagowski, J. M., Heterocyclic Chemistry, p. 129 (John Wiley, New York, 1960).

[9] Zollinger, H., Azo and Diazo Chemistry, pp. 108-109, 146-148 (Interscience Publishers, New York, 1961).

[10] (a) Roberts, J. D., Chem. Ber. 94, 273 (1961); (b) I. Lalezari, A. Shafice, and M. Yalpani, Tetrahedron Letters, 3049 (1969) (c) R. B. Woodward and C. Winter, Tetrahedron Letters, 2697 (1969) (d) C. Winter and J. Wiecko, Tetrahedron Letters, 155 (1969).

[11] Kuhn, R. and Trischman, H., Angew. Chem. 75, 294 (1963).

[12] Malkus, H., Battiste, M. A., and White, R. M., Chem. Commun. (1970) 479.

[13] Milligan, T. W. and Minor, B. C., J. Org. Chem. 27,4663 (1962).

[14] Smith, P. A. S., The Chemistry of Open-Chair Organic Nitrogen Compounds, Vol. 2, pp. 150-172 (W. A. Benjamin, Inc., New York, 1966)

[15] Sidgwick, N. V., The Organic Chemistry of Nitrogen, pp. 505531 (Oxford, London, 1966).

[16] Grundron, M. F. and Scott, M. D., J. Chem. Soc. 5674 (1964).

[17] Bloch, J. C., Tetrahedron Letters 4041 (1969).

(Paper 75A6-689) 